\title{
PEMANFAATAN TANAMAN OBAT KELUARGA JAHE (ZINGIBER OFFICINALE)SEBAGAI PENGGANTI OBAT KIMIA DI DUSUN TANJUNG ALE DESA KEMENGKING DALAM KECAMATAN TAMAN RAJO PROVINSI JAMBI
}

\author{
Medi Andriani, Erinda Rizki Putri, Afdonil Khomarul Fatta, Anggita Septia \\ Meriza, Dewi Permata Sari, Nada Anandita, Raiza Nolasari, Sri Puri Rizki, Wita \\ Astari
} Jurusan Farmasi,Fakultas Farmasi, STIKES Harapan Ibu Jambi, Jambi
erindarizkiputri@gmail.com

\begin{abstract}
Family Medicinal Plants (TOGA) is a very nutritious plant, especially in the health sector. Based on the data collection of disease complaints that the people in DUSUN TANJUNG ALE often feel, Kemingking Dalam Village, by $50 \%$ stated that colds and aches are the most frequent complaints. So the p11 Community Service Team developed RT TOGA community RT by adding Ginger (Zingiber Officinale). Ginger plants have many benefits, especially to overcome colds and strengthen the human body's immune system. The method used is (1) counseling treatment from medicinal plants (2) developing Family Medicinal Plants (TOGA) DUSUN TANJUNG ALE (3) processing ginger into infusion water and ginger candy. The results of the activity showed very high public enthusiasm in increasing knowledge about treatment using medicinal plants. It is hoped that the education provided can be applied as an alternative to overcoming public health problems.
\end{abstract}

Keywords: Family Medicinal Plants, Ginger (Zingiber Officinale), Traditional Medicines, Health, Public Health.

\begin{abstract}
Abstrak
Tanaman Obat Keluarga (TOGA) merupakan tanaman yang sangat berkhasiat terutama di bidang kesehatan. Berdasarkan pendataan keluhan penyakit yang sering dirasakan masyarakat di DUSUN TANJUNG ALE Desa Kemingking Dalam sebesar 50\% menyatakan masuk angin dan pegal-pegal adalah keluhan yang paling sering dirasakan. Sehingga TIM KKN p11 melakukan pengembangan TOGA masyarakat DUSUN TANJUNG ALE dengan menambahkan tanaman Jahe (Zingiber Officinale). Tanaman jahe memiliki banyak khasiat terutama mengatasi masuk angin serta memperkuat sistem imun tubuh manusia. Metode yang dilakukan yaitu (1) penyuluhan pengobatan dari tanaman obat (2) mengembangkan Tanaman Obat Keluarga (TOGA) DUSUN TANJUNG ALE (3) pengolahan jahe menjadi infus water dan permen jahe. Hasil kegiatan menunjukkan antusiasme masyarakat yang sangat tinggi dalam meningkatkan pengetahuan mengenai pengobatan menggunakan tanaman obat. Dengan demikian diharapkan edukasi yang diberikan dapat diterapkan sebagai salah satu alternatif untuk mengatasi masalah kesehatan masyarakat.
\end{abstract}

Kata kunci: Family Medicinal Plants, Ginger (Zingiber Officinale), Traditional Medicines, Health, Public Health. 
Medi Andriani, dkk. Pemanfaatan Tanaman Obat Keluarga Jahe (Zingiber Officinale)...

\section{PENDAHULUAN}

Tanaman obat pada dasarnya adalah sebidang tanah di halaman, taman, atau ladang yang digunakan untuk menumbuhkan tanaman dengan khasiat obat agar terpenuhi kebutuhan keluarga akan obat-obatan (Okimustava, 2018).

Nenek monyang bangsa Indonesia sejak dahulu telah menekuni pengobatan dengan memanfaatkan aneka tanaman yang terdapat di alam. Di daerah pedesaan, tradisi ini sebagian besar masih masih dipertahankan. TOGA amatlah sangat penting sehingga sering disebut juga sebagai apotek hidup. Pemanfaatan tanaman obat yang digunakan secara tepat tentunya tidak menimbulkan efek samping dibandingkan dengan obat-obatan yang berbahan sintesis.

Jika ada keluarga yang terserang penyakit, toga menjadi alternatif obat yang paling mudah di cari, dengan hanya memetik lalu meraciknya, tanaman tersebut dapat menjadi obat yang mujarab. Obat tradisional yang berasal dari tanaman memiliki efek samping yang jauh lebih rendah tingkat bahayanya di bandingkan obat-obatan kimia. Hal ini di sebabkan efek dari tanaman obat bersifat alami, tubuh manusia pun relatif lebih mudah menerima obat dari bahan tanaman dibandingkan dengan obat kimiawi.

Adanya penemuan-penemuan kodekteran yang berkembang pesat menyebabkan pengobatan tradisional berkesan kampungan dan ketinggalan zaman. Padahal banyak obat-obat modern yang dibuat dari tanaman obat, hanya saja peracikannya dilakukan secara klinis laboratoris sehingga berkesan modern.

Berbeda dengan obat kimia yang khusus mengobati satu penyakit, tanaman obat memiliki khasiat yang sangat beragam. Minsalnya, jahe dapat digunakan untuk batuk, pegal-pegal, kepala pusing, rematik, sakit pinggang, masuk angin, bronchitis, nyeri lambung, nyeri otot, vertigo, mual saat hamil, osteoarhritis gangguan sistem pencernaan, rasa sakit menstruasi, kanker, sakit jantung, fungsi otak terganggu, penyakit infeksi, asma, produksi air susu ibu rendah, gairah seksual rendah dan stamina tubuh rendah.

Pengobatan tradisional dengan bahan dari tanaman umumnya di kuasai secara turun-temurun. Setiap tanaman memiliki efek farmakologi yang sangat beragam, sehingga jenis tanamannya harus tepat. Pemakaian tanaman obat yang salah dapat berakibat fatal (Ir. Fauziyah, 2007). Sehingga TIM KKN p11 sangat berusaha agar edukasi dapat diserap dengan baik oleh masyarakan dan juga diharapkan masyarakat dapat menerapkan dengan tepat.

Pengembangan program TOGA ini di tunjukan agar warga DUSUN TANJUNG ALE menjadikan toga sebagi sarana alternatif pengobatan. Sehingga tidak kesulitan bagi warga untuk mendapatkan jenis tanaman obat yang dibutuhkan. Hal ini pula yang mendasari dikembangkanya program TOGA ini, di DUSUN TANJUNG ALE (Primadi, n.d.).

Pengabdian Masyarakat berupa Pengembangan TOGA dan pemanfaatan 
tanaman jahe merupakan upaya pemeliharaan kesehatan masyarakat secara alami khususnya di Dusun Tanjung Ale Kemengking Dalam. Sehingga diharapkan edukasi mengenai tanaman obat serta ketersediaan fasilitas tanaman obat yang telah ada dapat dijadikan alternatif dan memudahkan masyarakat untuk mengatasi masalah.

\section{METODE}

Kegiatan ini dilakukan di DUSUN TANJUNG ALE Desa Kemingkin Dalam Kecamatan Taman Rajo, Kabupaten Muaro Jambi. Metode yang dilakukan dalam kegiatan pengembangan tanaman obat dan pemanfaatan Jahe sebagai pengobatan yaitu:

1. Melakukan pendataan terhadap keluhan yang sering dirasakan masyarakat pada saat door to door mengenai DAGUSIBU

2. Edukasi Masyarakat mengenai manfaat jahe dan mengajak masyarakat untuk ikut serta dalam pengembangan TOGA sehingga lebih rapih

3. Sosialisasi pengolahan jahe sebagai obat (jahe dapat dijadikan sebagai infus water jahe dan permen jahe).

\section{HASIL DAN PEMBAHASAN}

Langkah awal yang dilakukan oleh TIM KKN p11 adalah peninjauan lapangan. Pertama-tama yaitu melakukan sosialisasi mengenai pengelolaan obat 'DAGUSIBU'. Namun TIM juga melakukan pendataan mengenai keluhan penyakit yang sering dirasakan oleh masyarakat. Setelah itu TIM mengkaji data sehingga memilih jahe untuk di promosikan sebagai tanaman obat yang sangat bermanfaaat dan memilih olahan jahe untuk di sosialisasikan ( pengolahan infus water jahe dan permen jahe).

Persiapan dilakukan dengan melihat keadaan TOGA yang ada di DUSUN TANJUNG ALE, kondisi TOGA kurang terawat dan banyak ditumbuhi dengan rumput-rumput yang cukup tinggi. Tanaman yang sudah ada pada TOGA DUSUN TANJUNG ALE seprti kunyit, jahe, laos, daun jarak, kumis kucing, dan berbagai jenis tumbuhan cabe lainnya. Setelah pembersihan TOGA dilakukan selanjutnya yaitu mengunjungi rumah pak RT untuk menghimbau para warga agar dapat memanfaatkan jahe sebagai permen dan untuk membuat infused water. Kegiatan ini dimulai dengan tahap persiapan dan kemudian meminta izin kepada pak DUSUN TANJUNG ALE dan selanjutnya adalah melakukan penyesuaian jadwal untuk kegiatan yang akan dilakukan.

Kegiatan pengembangan TOGA dan pemanfaatan dilakukan dengan melibatkan pemuda-pemudi DUSUN TANJUNG ALE dengan meminta bantuan kepada ketua pemuda-pemudi DUSUN TANJUNG ALE guna untuk mengarahkan anggotanya dalam membantu kegiatan ini, hal ini dilakukan agar dapat mempercepat terlaksananya kegiatan ini dan juga untuk menjalinkan keakraban kepada 
Medi Andriani, dkk. Pemanfaatan Tanaman Obat Keluarga Jahe (Zingiber Officinale)...

pemuda-pemudi DUSUN TANJUNG ALE.

\section{Pengembangan TOGA}

Setelah TOGA dibersihkan, dilakukan penanaman tumbuh tumbuhan obat seperti daun kelor dan lainnya, setelah itu dilakukan pengecatan pagar TOGA selama beberapa hari untuk mempercantik/memperindah TOGA DUSUN TANJUNG ALE. penanaman tumbuhan dan pengecatan pagar TOGA juga dibantu dengan warga DUSUN TANJUNG ALE guna untuk mempercepat kerja.

Edukasi yang telah diberikan kepada masyarakat yaitu mengenai cara pengolahan tanaman obat untuk dikonsumsi serta khasiatnya bagi tubuh. Edukasi diberikan melalui acara pengajian yang dilakukan ibu-ibu DUSUN TANJUNG ALE setiap minggu. Masyarakat sangat antusias menerima materi pengolahan tanaman obat. Hal ini dapat dilihat dari aktifnya bertanya jawab pada saat bersosialisasi. Adapun materi yang kami sampaikan mengenai pengolahan tanaman obat sebagai berikut:

1. Pembuatan permen jahe

Pembuatan perment jahe di DUSUN TANJUNG ALE, bahan-bahan yang digunakan air, jahe dan gula pasir. Langkah-langkah pembuatan perment jahe :

1) Potong-potong jahe

2) Masukkan air kedalam panci atau wadah

3) Masukkan gula

4) Rebus hingga mendidih (lalu saring ampasnya)
5) Kemudian rebus lagi aduk hingga mengental

2. Pembuatan infuse water

1) Siapkan jahe segar yang sudah dicuci bersih, dikupas dan di iris tipis-tipis

2) Tambahkan air dan masukkan kedalam lemari es selama 1 sampai 3 jam sebelum disajikan

Peserta yang mengikuti sosialisai pengolahan tanaman obat diharapkan dapat memerapkan serta mengajak masyarakat lainnya untuk mengolah tanaman obat dalam mengatasi keluhan yang dirasakan. Terutama pada saat mengalami gejala masuk angin dan pegal-pegal.

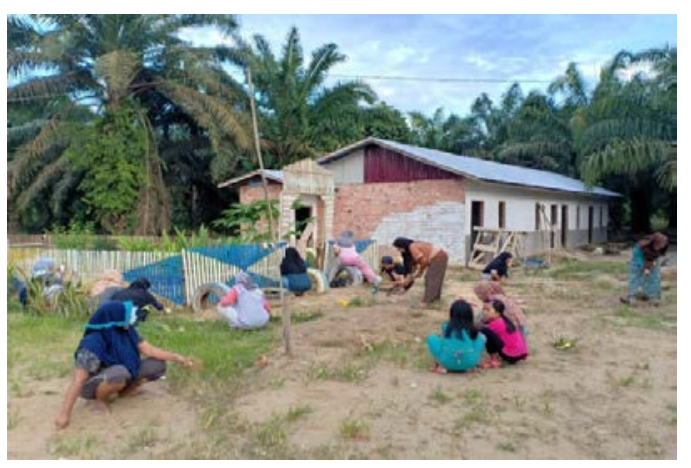

Gambar 1. Gontong royong bersama warga dalam pembersihan TOGA

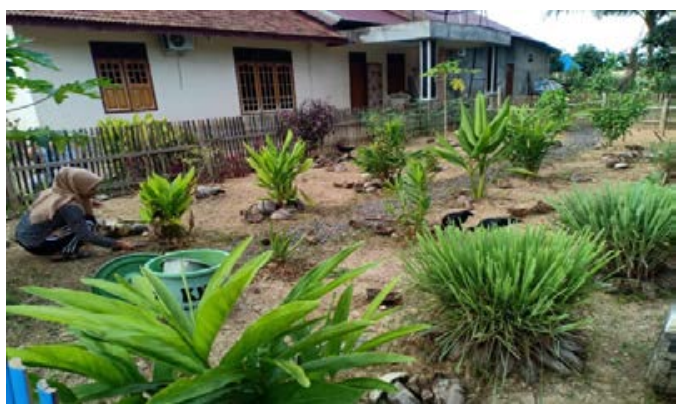

Gambar 2. Penambahan tanaman obat 


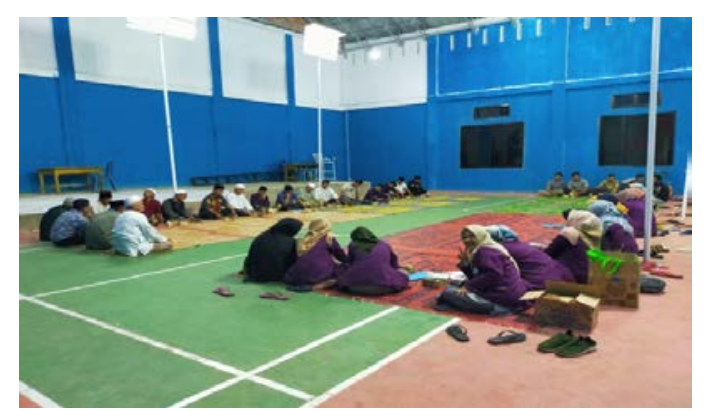

Gambar 3. Musyawarah kepada warga dan pemuda pemudi tentang khasiat jahe dan manfaatnya.

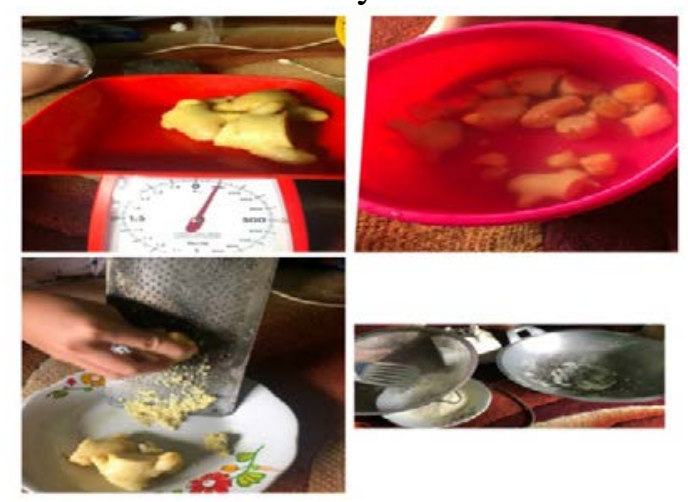

Gambar 4. Proses Pembuatan Permen Jahe

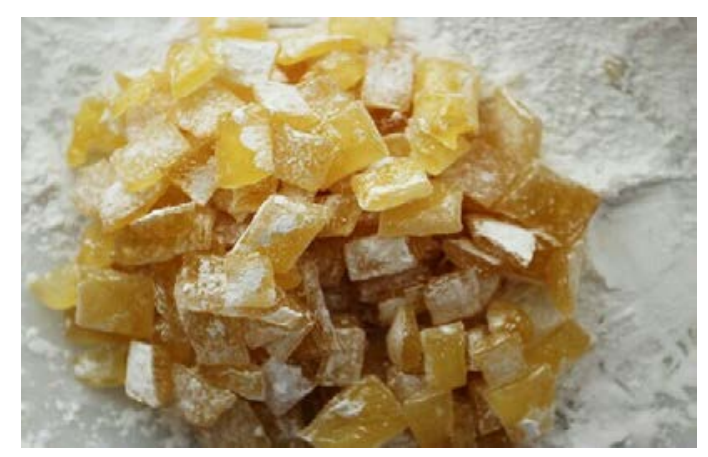

Gambar 5. Permen Jahe

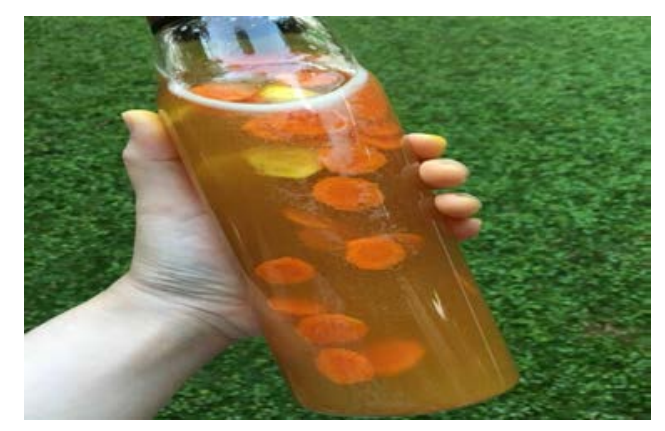

Gambar 6. Infused water

\section{SIMPULAN}

Pengembangan TOGA dan edukasi khasiat-khasiat dari TOGA yang telah diberikan kepada warga DUSUN TANJUNG ALE kemingking dalam memberikan dampak positif bagi warga DUSUN TANJUNG ALE kemingking dan meningkatkan kesadaran akan pentingnya tanaman TOGA sebagai obat-obatan. Selain itu dengan adanya tanaman TOGA ini masyarakat DUSUN TANJUNG ALE desa kemingking dalam mempunyai apotik hidup yang tidak jauh dari tempat tinggal, dan sangat banyak manfaatnya baik digunakan sebagai obat tradisional yang sifatnya mencegah atau mengobati berbagai macam penyakit akut hingga kronis sekalipun, dan bisa juga sebagai bumbu pelengkap masakan.

\section{UCAPAN TERIMA KASIH}

Tim penulis mengucapkan kepada ketua panitia KKN Stikes Harapan Ibu Jambi, Kepala Desa Kemengking Dalam, kepala DUSUN TANJUNG ALE Kemengking Dalam, Kepala Puskesmas kemengking dalam beserta staf, pembimbing institusi dan pembimbing lahan posko 11 desa kemengking dalam, seluruh perangkat desa kemengking dalam serta seluruh masyarakat desa kemengking dalam yang telah berkontribusi dalam kegiatan pengabdian ini sehingga terlaksana dengan baik. 
Medi Andriani, dkk. Pemanfaatan Tanaman Obat Keluarga Jahe (Zingiber Officinale)...

DAFTAR PUSTAKA

Ir. Fauziyah. M. (2008). Tanaman Obat Keluarga (TOGA). Depok. Penebar swadaya.

I. wayan. R. A. (2019). Manfaat Jahe Untuk Kesehatan. Widya Kesehatan Vol 1 No : 2 oktober 2019.

Okimustava, O. (2018). Pemanfaatan Tanaman Obat Keluarga Sebagai Pengganti Obat Kimia di Pedukuhan $V$ Kujon Lor,
Kranggan, Galur, Kulon Progo, Yogyakarta. Jurnal Pemberdayaan: Publikasi Hasil Pengabdian Kepada Masyarakat, 1(1), 79. https://doi.org/10.12928/jp.v1i1.3 13.

Primadi, A. L. (n.d.). Pelaksanaan Program Toga dalam Meningkatkan Kesehatan Masyarakat di Desa Ngestiharjo Kabupaten Bantul. 414-422. 